\title{
The Impact Of Industry Classification On The Valuation Accuracy Of Multiples In The South African Capital Market
}

WS Nel, University of Stellenbosch, South Africa BW Bruwer, University of Stellenbosch, South Africa NJ le Roux, University of Stellenbosch, South Africa

\begin{abstract}
Although multiples are used extensively in practice, empirical guidance in emerging markets is limited in this regard. In terms of valuation accuracy, the impact of peer group selection by way of industry classification in emerging markets has not yet been substantiated by research. This paper investigates the valuation performance of multiples over various industry classifications when valuing the equity of South African companies listed on the Johannesburg Stock Exchange for the period 2001 to 2010. The empirical results revealed that peer group selection based on a narrower industry classification could, on average, increase valuation accuracy by as much as $19.60 \%$.
\end{abstract}

Keywords: Emerging Markets; Industry Classification; Johannesburg Stock Exchange; Multiples; Valuation Accuracy

\section{INTRODUCTION}

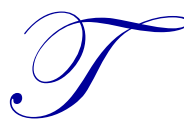

here is increasing international interest in corporate valuation practice in emerging markets, such as South Africa, which highlights the need for a best practice guide for investment practitioners in emerging markets (Bruner, Conroy, Estrada, Kritzman \& Li, 2002). However, despite the obvious need for greater academic rigour in this regard, very little empirical research has been conducted on valuation practices in emerging markets. Most of the international evidence is based on corporate valuation practice in the relatively deeply traded and liquid developed markets in the United States of America (USA) and Europe.

This research paper aims to make a contribution in the field of relative valuations, otherwise known as multiples, which are used extensively in practice (PwC, 2010; Minjina, 2008; Roosenboom, 2007; Damodaran, 2006b; Asquith, Mikhail \& Au, 2005; Bhojraj \& Lee, 2002). Multiples are used to value assets, based on how similar assets are valued in the market (Damodaran, 2002). Traditional multiples-based valuations rely on the following four steps (Damodaran, 2009; Schreiner \& Spremann, 2007): Firstly, the two value relevant measures are identified; i.e., the market price variable and a matching value driver. Secondly, a set of comparable companies, known as a peer group, is selected. Thirdly, a peer group multiple is estimated based on the selection in step two. Lastly, the peer group multiple is applied to the target company's value driver to determine the value of the target company's equity.

The focus of this paper is on the ability of the peer group selection in step two to increase the valuation accuracy of multiples. The primary aim is to establish whether peer group selection by narrower industry classification will increase the valuation accuracy of multiples. The secondary aim is to determine the potential improvement in valuation accuracy that industry narrowing may offer vis-à-vis wider industry classifications. The third aim is to determine the most optimal industry definition for peer group selection purposes. To this end, 16 multiples are constructed, covering four value driver categories; namely, earnings, book value, revenue and cash flow. 
Section 2 presents the literature review, followed by the data selection in section 3 and a discussion of the research methodology, including the mathematical definition of the concept of valuation errors, in section 4 , which serves as the premise for this research. The empirical results of the research are presented in section 5. Concluding remarks are offered in the final section.

\section{LITERATURE REVIEW}

Peer group selection can be based on a set of comparable companies or comparable transactions (Stowell, 2010). The method which relies on the selection of a set of comparable companies assumes that companies within the same industry are relatively homogeneous; i.e., they have similar financial and operational characteristics, which would imply that the companies have similar prospects for key value drivers such as profitability, growth and risk. The method which relies on the selection of comparable transactions, which is normally used for valuing merger and acquisition deals, selects historical corporate transactions in the same industry or country as comparables (Pratt, 2005). However, as a result of data limitations, the comparable transactions method is less appropriate for statistical analysis. Consequently this paper will focus on the selection of comparable companies.

Statistical logic would suggest that not one, but several, comparable companies should be selected. The logic is that the standard deviation of the valuation errors, when selecting one company vis-à-vis the standard deviation when selecting several companies, will be higher (Alford, 1992). The importance of the selection of comparable companies is highlighted in various studies, which also indicate the different areas of application thereof. Despite its obvious application when employing multiples, the selection of comparable companies is also prominent in discounted cash flow analysis, for example, where it is used to estimate a company's cost of capital (Fuller \& Kerr, 1981). Various researchers also advocate the importance of comparable companies when investigating the contagion effect; i.e., where actions that affect the value of one company in a specific industry impact on the value of other companies in the same industry (Bhojraj \& Lee, 2002; Eberhart, 2001; Fenn \& Cole, 1994; Lang \& Stulz, 1992).

Despite the wide application thereof in practice, very little theory is available on how, and why, certain comparable companies should be selected in certain circumstances. There are two schools of thought in this regard (Bhojraj \& Lee, 2002). The first school of thought defines comparable companies simply as companies in similar industries. Consequently, since companies in similar industries display similar risk and earnings growth characteristics, comparable companies are selected based on industry classification (Damodaran, 2006a; Alford, 1992). The second school of thought argues that a comparable company set should be compiled based on valuation fundamentals (Dittmann \& Weiner, 2005; Goedhart, Koller \& Wessels, 2005). The valuation fundamentals school of thought favours the selection of comparable companies on the basis of similar economic variables such as profitability, growth and risk, instead of industry classification. The focus of this paper is on the selection of a set of comparable companies based on industry classification.

Since different industries display different operational and financial characteristics, industry classification is crucial in the identification of the peer group of companies. Empirical evidence should guide preferences in this regard and one would be inclined to argue that a narrower industry classification should more closely align companies with more similar operational and financial characteristics. The implicit assumption is therefore that a narrower industry classification should render more accurate valuations. However, a narrowly defined industry classification may create a situation where an insufficient number of companies is available within such a narrowly defined classification to accommodate empirical testing. Researchers in the USA, for example, often encounter this problem when they use 4-digit codes from the USA Compustat database. In order to overcome this problem, homogeneity is sacrificed to ensure a sufficiently large peer group by selecting comparables based on a broader industry definition, such as a 3 -digit industry classification. ${ }^{1}$

\footnotetext{
${ }^{1}$ The 4-digit code classification system, which is used internationally, assigns a 4-digit code to each company. The first digit specifies the industry (widest classification), the second digit specifies the supersector, the third digit specifies the sector and the fourth digit specifies the subsector (narrowest classification). The McGregor Bureau of Financial Analysis (BFA) classification system, which is used in this paper, is similar to international classification systems.
} 
Most existing studies build on the comparable company principle work of Alford (1992), who found that selecting comparable companies based on 3-digit Standard Industry Classification (SIC) codes is reasonably effective. According to Alford's research results, a narrower industry classification improves the valuation accuracy of multiples, but with diminishing significance as the industry definition is refined further. Alford also concluded that controlling for risk (via company size) and earnings growth (via return on equity) has little effect on valuation accuracy. He further noted that, when selecting comparable companies based on industry classification, the valuation accuracy is greater for larger companies than for smaller companies. However, Alford's research was limited to USA companies and covered only three years; namely, 1978, 1982 and 1986.

In a similar study on USA and European companies, Schreiner (2007) found that forming a smaller, but more homogenous peer group; i.e., by narrowing the industry classification from 1-digit to 2-digit to 3-digit industry codes, improved the valuation accuracy of multiples. This study included accrual-, book value- and cash flow-based multiples. When employing a median absolute valuation error and a 15\% fraction error (FRE) range, the empirical results indicated that a narrower industry classification; i.e., narrowing the industry classification from 1-digit to 3digit industry codes, increased valuation accuracy, on average, by $8.60 \%$ and $17.17 \%$, respectively (Schreiner, 2007).

Henschke and Homburg (2009) obtained similar results when they tested the impact of a narrower industry classification on the valuation accuracy of USA-based companies over the period 1986 to 2004. They compared, among others, the valuation accuracy of four earnings-based multiples; namely, price-to-book value, price-toCompustat-earnings, price-to-forecasted-earnings and price-to-Institutional Brokers Estimation System (IBES)earnings. Their research results indicated that, for $75 \%$ of the observations, a narrower industry classification resulted in an increase in valuation accuracy.

Research conducted by Berkman, Bradhury and Ferguson (2000) in New Zealand presents evidence to the contrary. However, their evidence was based on a small sample of 45 newly listed companies on the New Zealand Stock Exchange. The authors also conceded that their findings were based on data that were difficult to obtain in a thinly traded capital market, which may have obscured the results.

Although the majority of evidence from these studies indicates that a narrower industry classification results in an increase in valuation accuracy, the international literature focuses on developed economies, while shedding little light on emerging markets. No such research has, for example, yet been conducted in South Africa. Consequently, this research paper aims to address the lack of empirical evidence in this regard and to add an emerging market perspective to the existing literature.

\section{DATA SELECTION}

The following variables were extracted from the McGregor BFA database: Market capitalisation (MCap), Shares in issue, Gross profit (GP), Earnings before interest, tax, depreciation and amortisation (EBITDA), Earnings before interest and tax (EBIT), Profit after tax (PAT), Profit before tax (PBT), Headline earnings (HE), Total assets (TA), Invested capital (IC), Book value of equity (BVE), Revenue (R), Cash generated by Operations (CgbO), Increase/decrease in working capital, Net cash inflow from operating activities (NCIfOA)), Net cash inflow from investment activities (NCIfIA), Ordinary dividends (OD), Taxation paid, Fixed assets acquired, Net interest paid/received, Secondary tax on companies, Capital profits/losses on financial assets, Normal taxation included in extraordinary items, Total profit of an extraordinary nature, Industry (IND), Supersector (SUP), Sector (SEC) and Subsector (SUB). ${ }^{2}$

Company-year observations for these variables for the period 2001 to 2010 were extracted from the McGregor BFA database. The companies were selected based on three criteria: 1) All multiples are positive; i.e., multiples with negative values were discarded, 2) The companies have at least three years of positive company year multiples, and 3) Each industry classification category has at least four observations that meet criteria 1) and 2)

\footnotetext{
${ }^{2}$ Annexure A contains a complete list of acronyms/abbreviations, while key variables are defined in Annexure B. 
above. $^{3}$

The first condition eliminates unrealistic multiples that cannot be used. The second condition ensures that selected companies have a reasonable history as a going concern and the third ensures that the number of companies within each industry classification is not prohibitively small, preventing the situation where there are too few observations to warrant a realistic mean calculation. The final population of observations represents approximately $71 \%$ of the total number of listed companies on the Johannesburg Stock Exchange (JSE) as at 31 December 2010 and approximately $91 \%$ of the market capitalisation of the companies listed on the JSE at the same date, which serves as a fair representation for the conclusions drawn.

The number of observations differed for each multiple and industry classification, depending on how well the multiples satisfied the criteria stipulated above. As a result, the multiples have different population sizes over different industry classifications, varying between 759 and 2747 observations. The total population of multiples included 125,637 observations, which, depending on the specific combination of multiple and industry classification for the period 2001 to 2010, had varying sample sizes. These observations were used to calculate 16 multiples; i.e., multiples where market price $(\mathrm{P})$ was used as the market price variable. Although various potential combinations of $\mathrm{P}$ and value drivers exist, the focus for the purpose of this paper, was on multiples within each of the four most popular value driver categories; namely, earnings, book value, revenue and cash flows (Nel, 2010; PwC, 2010; Nel, 2009a; Liu, Nissim \& Thomas, 2002b; Cheng \& McNamara, 2000). The framework of multiples; i.e., the ratio of P to the respective value drivers, that was used in the analysis is summarised in Table 1.

Table 1: Framework of Multiples

\begin{tabular}{|l|c|c|c|}
\hline \multirow{2}{*}{ Earnings } & Book Value & Ralue Drivers & Cash Flow \\
\hline GP & TA & R & NCIfOA \\
\hline EBITDA & IC & NCIfIA \\
\hline EBIT & BVE & OD \\
\hline PAT & & FCFE \\
\hline PBT & & FCFF \\
\hline P - Market price & \\
GP - Gross profit & \\
EBITDA - Earnings before interest, tax, depreciation and amortisation & \\
EBIT - Earnings before interest and tax & \\
PAT - Post-tax earnings & \\
PBT - Pre-tax earnings & \\
HE - Headline earnings & \\
TA - Total assets & \\
IC - Invested capital \\
BVE - Book value of equity \\
R - Revenue \\
CgbO - Cash generated by operations \\
NCIfOA - Net cash inflow from operating activities \\
NCIfIA - Net cash inflow from investment activities \\
OD - Ordinary dividends \\
FCFE - Free cash flow to equity \\
FCFF - Free cash flow to the firm
\end{tabular}

\footnotetext{
3 Although many companies' industry classifications have changed over the past 10 years, for the purposes of this analysis, companies were allocated to the industries where they resided as at 31 December 2010.
} 


\section{RESEARCH METHODOLOGY}

Valuations based on multiples assume that the actual equity value $\left(V_{i t}^{e}\right)$ of a company $(i)$ at a given point in time $(t)$ is equal to the product of a multiple $\left(\lambda_{t}^{e}\right)$ and a specific value driver $\left(\alpha_{i t}\right)$ at that specific point in time, so that

$$
V_{i t}^{e}=\lambda_{t}^{e} \cdot \alpha_{i t}
$$

The aim of this section of the research is to establish the ability of valuations based on equation (1) to approximate actual share values. Firstly, the data is extracted from the McGregor BFA database and screened according to the criteria stipulated in section 3.

Next, an out-of-sample peer group multiple $\left(\hat{\lambda}_{t}^{e}\right)$ is estimated for each company by calculating the harmonic mean of all the other remaining companies in the industry classification category concerned for that specific multiple. The estimated subsector P/GP multiple for company A, for example, in a subsector that contains companies A to E, will be equal to the harmonic mean of the P/GP multiples of companies B to E. The harmonic mean is used in this study to estimate peer group multiples since it avoids the upward bias of the arithmetic mean, which, as emerged in this study, can be significant. ${ }^{4}$

The application of an industry-specific approach to multiples is well established by research (Nel, 2009a; Nel, 2009b; Goedhart, Koller and Wessels, 2005; Liu, Nissim \& Thomas, 2002a; Fernández, 2001; Barker, 1999). Although it may seem necessary to pursue a more diligent peer group selection process by also considering factors such as company size and expected growth rates, the primary focus of this paper is to establish the impact of a narrower industry classification on the valuation accuracy of multiples. Peer group selection will be refined through the four McGregor BFA industry classification categories; namely, IND, SUP, SEC and SUB. The estimated peer group multiple of each company ( $\left.\hat{\lambda}_{t}^{e}\right)$, is then multiplied by the company's actual value driver $\left(\alpha_{i t}\right)$ to calculate an equity value prediction $\left(\hat{V}_{i t}^{e}\right)$ :

$$
\hat{V}_{i t}^{e}=\hat{\lambda}_{t}^{e} \cdot \alpha_{i t}
$$

Subtracting equation (2) from equation (1) produces (3) for the calculation of the error margin (valuation error):

$$
\hat{V}_{i t}^{e}-V_{i t}^{e}
$$

Since companies with higher values will tend to have higher valuation errors, (3) will not be independent of value. It is anticipated that expressing (3) proportionally to $V_{i t}^{e}$ will improve the efficacy of the peer group multiple estimate (Beatty, et al. 1999). The standardised form of (3), $\varepsilon_{i t}$, is therefore expressed proportionally to $V_{i t}^{e}$, where

\footnotetext{
${ }^{4}$ Although there is a lack of academic consensus regarding which averaging procedure constitutes best practice (Dittman \& Maug, 2008), most researchers regard the harmonic mean as a viable and unbiased estimator (Bhojraj \& Lee, 2002 ; Liu, et al. 2002b; Beatty, Riffe \& Thompson, 1999).
} 


$$
\varepsilon_{i t}=\left|\frac{\hat{V}_{i t}^{e}-V_{i t}^{e}}{V_{i t}^{e}}\right|
$$

The valuation errors are calculated for each company year and subsequently aggregated. ${ }^{5}$ Absolute valuation errors are used since the results of central tendency measures such as the mean will be obscured if positive and negative valuation errors are netted, which may result in artificially low valuation errors. The superior industry classification; i.e., the industry classification that produces the most accurate equity valuation, will normally be the one with the lowest summarised valuation error. To this end, four measures of location were used to analyse the pooled observations; namely, the mean, the $25 \%$ percentile, the median and the $75 \%$ percentile. An additional two measures; namely, the $15 \%$ and $25 \%$ fractional error (FRE) ranges, were employed to gauge the impact of a narrower industry classification on the valuation accuracy of multiples. However, these two FRE ranges measure the percentage of valuation errors below $15 \%$ and $25 \%$, respectively. Therefore, a higher summarised score (percentage) would indicate an increase in valuation accuracy, as opposed to the first four summarised measures, where a lower score indicates an increase in valuation accuracy. This allows comparison with various international studies (Herrmann \& Richter, 2003; Lie \& Lie, 2002; Liu, et al. 2002a; Kim \& Ritter, 1999; Kaplan \& Ruback, 1995).

The performance of the multiples over the four industry classifications was evaluated by comparing the locality and dispersion of their respective valuation errors. An industry value chain was subsequently created, which indicates the extent to which the valuation accuracy of multiples improved as the industry classification was narrowed. The industry value chain indicates the potential percentage improvement (IMP) in valuation accuracy that may be secured by employing a more narrowly classified peer group multiple, i.e., by substituting the widest industry classification with the narrowest one.

\section{EMPIRICAL RESULTS}

This section deals with the locality and dispersion of valuation errors of the selected 16 multiples. The key measures used to calculate the locality and the dispersion of valuation errors were the mean (central tendency), the $25 \%$ percentile, the median (central tendency), the $75 \%$ percentile and the 0.15 and 0.25 FREs. $^{6}$ These measures are contained in Table 2.

Table 2: Absolute Valuation Errors When The Industry Classification Is Narrowed: Descriptive Statistics

\begin{tabular}{|c|c|c|c|c|c|c|c|}
\hline & $\mathbf{N}$ & Mean & P25\% & Median & P75\% & FRE0.15 & FRE0.25 \\
\hline \multicolumn{8}{|l|}{ P/GP } \\
\hline IND & 2261 & 1.2086 & 0.3229 & 0.5801 & 0.8271 & 0.1176 & 0.1955 \\
\hline SUP & 2228 & 1.2809 & 0.2875 & 0.5589 & 0.8449 & 0.1355 & 0.2127 \\
\hline SEC & 2097 & 1.5850 & 0.2754 & 0.5277 & 0.8372 & 0.1388 & 0.2265 \\
\hline SUB & 1683 & 1.6072 & 0.2684 & 0.5201 & 0.8834 & 0.1450 & 0.2365 \\
\hline \multicolumn{8}{|c|}{ P/EBITDA } \\
\hline IND & 2393 & 1.6314 & 0.3357 & 0.5971 & 0.8284 & 0.1045 & 0.1776 \\
\hline SUP & 2376 & 1.7388 & 0.2764 & 0.5527 & 0.8338 & 0.1317 & 0.2252 \\
\hline SEC & 2277 & 2.2797 & 0.2673 & 0.5317 & 0.8344 & 0.1401 & 0.2328 \\
\hline SUB & 1831 & 1.7757 & 0.2418 & 0.5116 & 0.8672 & 0.1524 & 0.2561 \\
\hline \multicolumn{8}{|c|}{ P/EBIT } \\
\hline IND & 2330 & 2.4075 & 0.3097 & 0.5578 & 0.8330 & 0.1180 & 0.1983 \\
\hline SUP & 2313 & 2.7723 & 0.2445 & 0.5180 & 0.8351 & 0.1587 & 0.2559 \\
\hline SEC & 2215 & 2.7891 & 0.2312 & 0.4885 & 0.8210 & 0.1648 & 0.2655 \\
\hline SUB & 1789 & 1.9320 & 0.2195 & 0.4880 & 0.8464 & 0.1738 & 0.2778 \\
\hline
\end{tabular}

${ }^{5}$ Functions for the calculation of $\varepsilon_{i t}$ and the statistical analysis thereof were developed in the R-package (R Development Core Team, 2012), an open source programming language that lends itself to statistical analysis and graphics.

${ }^{6}$ The 5\%, 10\%, 90\% and 95\% percentiles, although not shown here, rendered similar results to that of the $25 \%$ and $75 \%$ percentiles. 
Table 2 - continued

\begin{tabular}{|c|c|c|c|c|c|c|c|}
\hline & $\mathbf{N}$ & Mean & $\mathbf{P 2 5 \%}$ & Median & P75\% & FRE0.15 & FRE0.25 \\
\hline \multicolumn{8}{|c|}{ P/PAT } \\
\hline IND & 2173 & 2.6109 & 0.2682 & 0.5498 & 0.8556 & 0.1275 & 0.2287 \\
\hline SUP & 2157 & 2.9193 & 0.2291 & 0.5127 & 0.8487 & 0.1572 & 0.2703 \\
\hline SEC & 2059 & 2.7160 & 0.2220 & 0.4890 & 0.8393 & 0.1622 & 0.2749 \\
\hline SUB & 1649 & $\mathbf{1 . 7 7 8 3}$ & 0.2273 & 0.4853 & 0.8642 & \begin{tabular}{|l|}
0.1656 \\
\end{tabular} & 0.2741 \\
\hline \multicolumn{8}{|c|}{ P/PBT } \\
\hline IND & 2215 & 2.8513 & 0.2548 & 0.5410 & 0.8572 & 0.1418 & 0.2470 \\
\hline SUP & 2198 & 3.3114 & 0.2211 & 0.5194 & 0.8424 & 0.1724 & 0.2784 \\
\hline SEC & 2099 & 3.0565 & 0.2228 & 0.4844 & $\begin{array}{l}0.8360 \\
\end{array}$ & 0.1701 & 0.2758 \\
\hline SUB & 1677 & 1.8166 & 0.2204 & 0.4705 & 0.8566 & \begin{tabular}{|l|}
0.1777 \\
\end{tabular} & 0.2755 \\
\hline \multicolumn{8}{|l|}{ P/HE } \\
\hline IND & 2225 & 1.7350 & 0.1839 & 0.3853 & 0.7263 & 0.2090 & 0.3384 \\
\hline SUP & 2209 & 1.6420 & 0.1704 & $\begin{array}{l}0.3668 \\
\end{array}$ & 0.7329 & 0.2205 & 0.3603 \\
\hline SEC & 2110 & $\mathbf{1 . 3 9 7 6}$ & 0.1666 & 0.3676 & 0.7068 & 0.2242 & 0.3630 \\
\hline SUB & 1704 & 1.7731 & 0.1686 & 0.3770 & 0.7356 & 0.2224 & 0.3568 \\
\hline \multicolumn{8}{|l|}{ P/TA } \\
\hline IND & 2747 & 1.2581 & 0.4070 & 0.6938 & 0.8932 & 0.0764 & 0.1405 \\
\hline SUP & 2727 & 1.7611 & 0.3710 & 0.6662 & 0.8938 & 0.0895 & 0.1624 \\
\hline SEC & 2650 & 2.1060 & 0.3358 & 0.6365 & 0.9036 & 0.1140 & 0.1864 \\
\hline SUB & 2224 & 1.8895 & 0.3376 & 0.6242 & 0.9001 & 0.1097 & 0.1808 \\
\hline \multicolumn{8}{|l|}{ P/IC } \\
\hline IND & 2745 & 1.2480 & 0.4386 & 0.6997 & 0.8967 & 0.0769 & 0.1308 \\
\hline SUP & 2725 & 1.5371 & 0.3859 & 0.6871 & 0.9055 & 0.0855 & 0.1483 \\
\hline SEC & 2649 & 1.8597 & 0.3575 & 0.6597 & 0.9164 & 0.1023 & 0.1725 \\
\hline SUB & 2223 & 2.0784 & 0.3652 & 0.6441 & 0.9129 & 0.0994 & 0.1615 \\
\hline \multicolumn{8}{|c|}{ P/BVE } \\
\hline IND & 2467 & 1.4504 & 0.3793 & 0.6833 & 0.9163 & 0.0965 & 0.1585 \\
\hline SUP & 2447 & 2.1727 & 0.3526 & 0.6756 & 0.9197 & 0.1005 & 0.1737 \\
\hline SEC & 2356 & 2.8868 & 0.3558 & 0.6836 & 0.9224 & 0.1091 & 0.1744 \\
\hline SUB & 1938 & 1.8129 & 0.3391 & 0.6556 & 0.9371 & 0.1151 & 0.1873 \\
\hline \multicolumn{8}{|l|}{$\mathbf{P} / \mathbf{R}$} \\
\hline IND & 2441 & 1.3523 & 0.4331 & 0.7420 & 0.9255 & 0.0709 & 0.1241 \\
\hline SUP & 2421 & 1.7681 & 0.4039 & 0.6978 & 0.9203 & 0.0838 & 0.1417 \\
\hline SEC & 2318 & 2.2917 & 0.3876 & 0.6924 & 0.9206 & 0.0902 & 0.1544 \\
\hline SUB & 1884 & 2.8187 & 0.3905 & 0.7071 & 0.9395 & 0.0860 & 0.1423 \\
\hline \multicolumn{8}{|c|}{ P/CgbO } \\
\hline IND & 2217 & 1.0575 & 0.3051 & 0.5639 & 0.8429 & 0.1141 & 0.2025 \\
\hline SUP & 2201 & 1.3282 & 0.3010 & 0.5557 & 0.8597 & 0.1172 & 0.2099 \\
\hline SEC & 2060 & 1.5485 & 0.2907 & 0.5419 & $\mathbf{0 . 8 3 9 5}$ & 0.1136 & 0.2117 \\
\hline SUB & 1685 & 1.2046 & 0.2903 & 0.5556 & 0.8811 & 0.1282 & 0.2178 \\
\hline \multicolumn{8}{|c|}{ P/NCIfOA } \\
\hline IND & 2002 & 1.4313 & 0.3695 & 0.6904 & 0.9227 & 0.0904 & 0.1523 \\
\hline SUP & 1987 & 2.0590 & 0.3628 & 0.6659 & 0.9228 & 0.1007 & 0.1676 \\
\hline SEC & 1888 & 2.0587 & 0.3458 & 0.6599 & 0.9251 & 0.1065 & 0.1748 \\
\hline SUB & 1459 & 2.1974 & 0.2922 & 0.6607 & 0.9440 & 0.1076 & 0.1864 \\
\hline \multicolumn{8}{|c|}{ P/ NCIfIA } \\
\hline IND & 1144 & 2.4148 & 0.5210 & 0.8216 & 0.9595 & 0.0629 & 0.1119 \\
\hline SUP & 1129 & 2.6679 & 0.4976 & 0.8100 & 0.9737 & 0.0735 & 0.1275 \\
\hline SEC & 1042 & 14.8500 & 0.4772 & 0.8016 & 0.9787 & 0.0729 & 0.1238 \\
\hline SUB & 759 & 4.4714 & 0.4774 & 0.8520 & 0.9985 & 0.0856 & $\mathbf{0 . 1 3 3 1}$ \\
\hline \multicolumn{8}{|c|}{ P/OD } \\
\hline IND & 1721 & 19.3454 & 0.3359 & 0.6466 & 0.9415 & 0.1023 & 0.1732 \\
\hline SUP & 1700 & 46.5190 & 0.3286 & 0.6457 & $\mathbf{0 . 9 3 0 7}$ & 0.1106 & 0.1859 \\
\hline SEC & 1539 & 51.2018 & 0.2944 & 0.6290 & 0.9361 & 0.1209 & 0.2086 \\
\hline SUB & 1202 & 1.2065 & 0.2922 & 0.6004 & 0.9698 & 0.1348 & 0.2171 \\
\hline
\end{tabular}


Table 2 - continued

\begin{tabular}{|c|c|c|c|c|c|c|c|}
\hline & $\mathbf{N}$ & Mean & $\mathbf{P 2 5 \%}$ & Median & P75\% & FRE0.15 & FRE0.25 \\
\hline \multicolumn{8}{|c|}{ P/FCFE } \\
\hline IND & 1413 & 1.8147 & 0.4390 & 0.7638 & 0.9438 & 0.0807 & 0.1309 \\
\hline SUP & 1401 & 1.9634 & 0.4178 & 0.7346 & 0.9563 & 0.0878 & 0.1363 \\
\hline SEC & 1277 & 3.0326 & 0.3934 & 0.7213 & 0.9654 & 0.0838 & 0.1464 \\
\hline SUB & 941 & 2.3423 & 0.3376 & 0.7432 & 0.9833 & 0.0786 & 0.1456 \\
\hline \multicolumn{8}{|c|}{ P/FCFF } \\
\hline IND & 1586 & 1.3765 & 0.3587 & 0.6796 & 0.9071 & 0.0939 & 0.1658 \\
\hline SUP & 1574 & 1.4325 & 0.3640 & 0.6860 & 0.9219 & 0.1061 & 0.1798 \\
\hline SEC & 1427 & 1.5482 & 0.3485 & 0.6632 & 0.9237 & 0.1044 & 0.1843 \\
\hline SUB & 1053 & 1.7767 & 0.3333 & 0.6980 & 0.9556 & 0.1083 & 0.1909 \\
\hline
\end{tabular}

IND - Industry; SUP - Supersector; SEC - Sector; SUB - Subsector; N - Number of observations;

P25\% - 25\% percentile; P75\% - 75\% percentile; FRE 0.15 - 15\% FRE range; FRE 0.25 - 25\% FRE range;

$\mathrm{P}$ - Market price; GP - Gross profit; EBITDA - Earnings before interest, tax, depreciation and amortisation;

EBIT - Earnings before interest and tax; PAT - Profit after tax; PBT - Profit before tax; HE - Headline earnings;

TA - Total assets; IC - Invested capital; BVE - Book value of equity; R - Revenue;

$\mathrm{CgbO}$ - Cash generated by operations; NCIfOA - Net cash inflow from operating activities;

NCIfIA - Net cash inflow from investment activities; OD - Ordinary dividends; FCFE - Free cash flow to equity;

FCFF - Free cash flow to the firm; Highlighted figures - Most optimal industry classification

\subsection{Descriptive Statistics}

The valuation performance of the 16 multiples was compared over various industry classifications in order to ascertain whether a narrower industry classification results in more accurate valuations. Four pools of valuation errors were estimated based on four industry classifications; namely, IND, SUP, SEC and SUB. As is evident from Table 2 and the boxplots in Figure 1, the number of company year observations $(\mathrm{N})$ declined as the industry classification was narrowed from IND through to SUB, which had a bearing on the mean (depicted by asterisks in Figure 1) and the measures of dispersion. The boxplots in Figure 1 and Figure 2 appear in order of performance, based on the median absolute valuation error; i.e., the multiples are ranked from those with the highest increase in valuation accuracy, to those with the lowest increase in valuation accuracy. Note, the notches in the boxplots in Figure 1 and Figure 2 indicate approximate 95\% confidence intervals for the respective medians, which allow statistical inference.

The measures of locality are sensitive to outliers (depicted as bubbles above the top whiskers in Figure 1), of which there were quite a few. Apart from the effect that the outliers had on the measures of locality and dispersion per se, the impact was magnified within the smaller samples; i.e., within the more narrowly defined industry classifications, which may partly explain why the mean offered inconsistent results. The boxplots in Figure 1 illustrate that the data are not normally distributed, but positively skewed; i.e., all 16 boxes are located significantly closer to the bottom whiskers. This is the primary reason why researchers generally attach less value to the mean (Bhojraj \& Lee, 2002; Liu, et al. 2002b; Beatty, et al. 1999). Therefore, although the mean is shown in the analysis, its inconsistent results over industry narrowing can be traced to its sensitivity to outliers and a declining sample size, as opposed to a measure of central tendency, such as the median, for example.

An interesting phenomenon depicted by the boxplots is that the lower boundary of the box ( $25^{\text {th }}$ percentile) and the upper boundary of the box $\left(75^{\text {th }}\right.$ percentile) generally divert, which suggests that the more accurate valuations prior to industry narrowing became even more accurate with industry narrowing, and, vice versa; i.e., the less accurate valuations prior to industry narrowing became even less accurate with industry narrowing. On average, $81 \%$ of the variables tested demonstrated this tendency over the four industry classifications. This is evident from the widening interquartile ranges in the boxplots in Figure 2. The median of the upper $50 \%$ of observations increased, therefore, as the industry classification was narrowed, while the median of the bottom $50 \%$ of observations, decreased. The latter is in line with the median of all the observations, which also decreased as the industry classification was narrowed. 

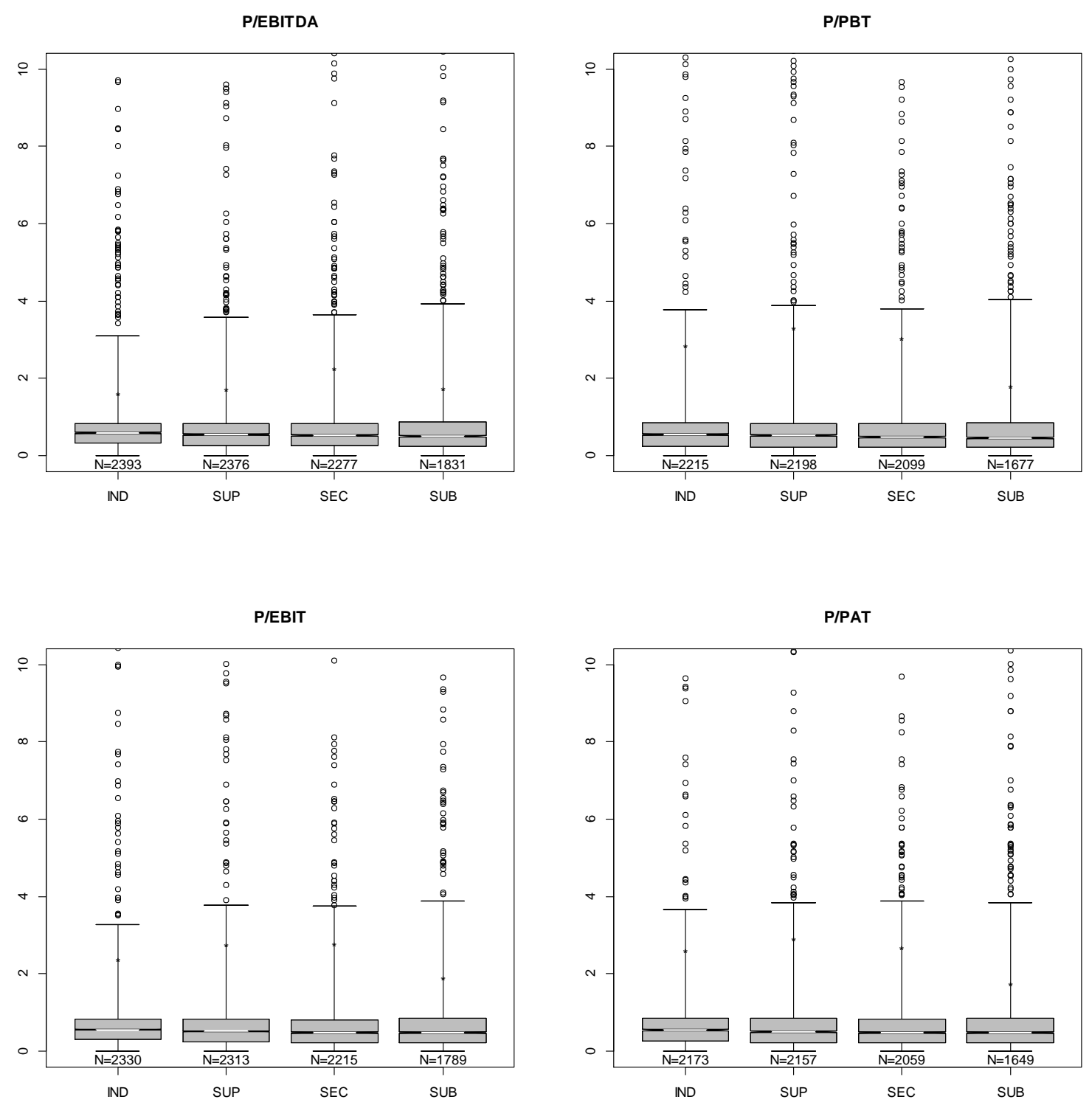

Figure 1: Valuation Accuracy Of Multiples: Descriptive Statistics 

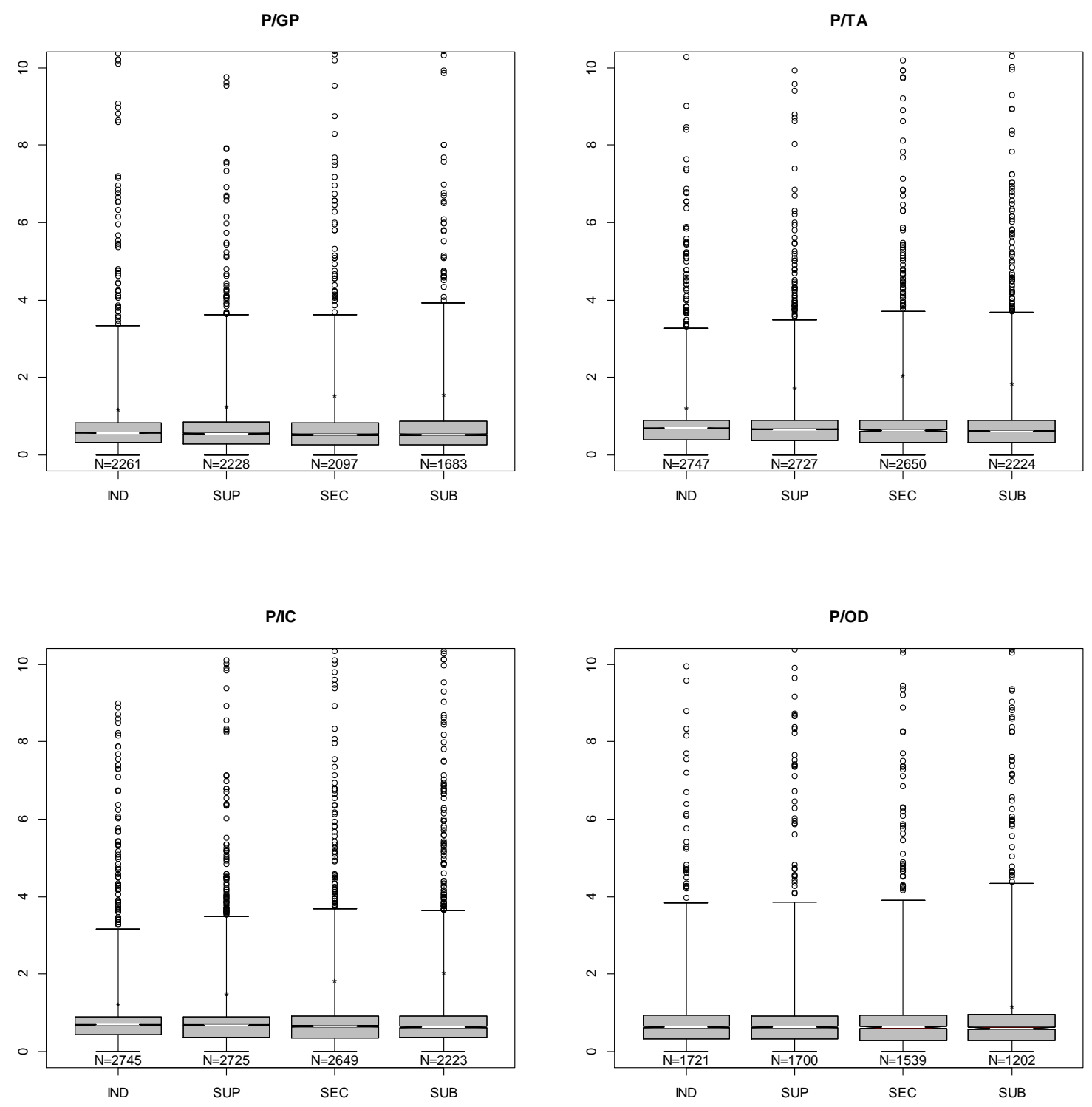

Figure 1 - continued 

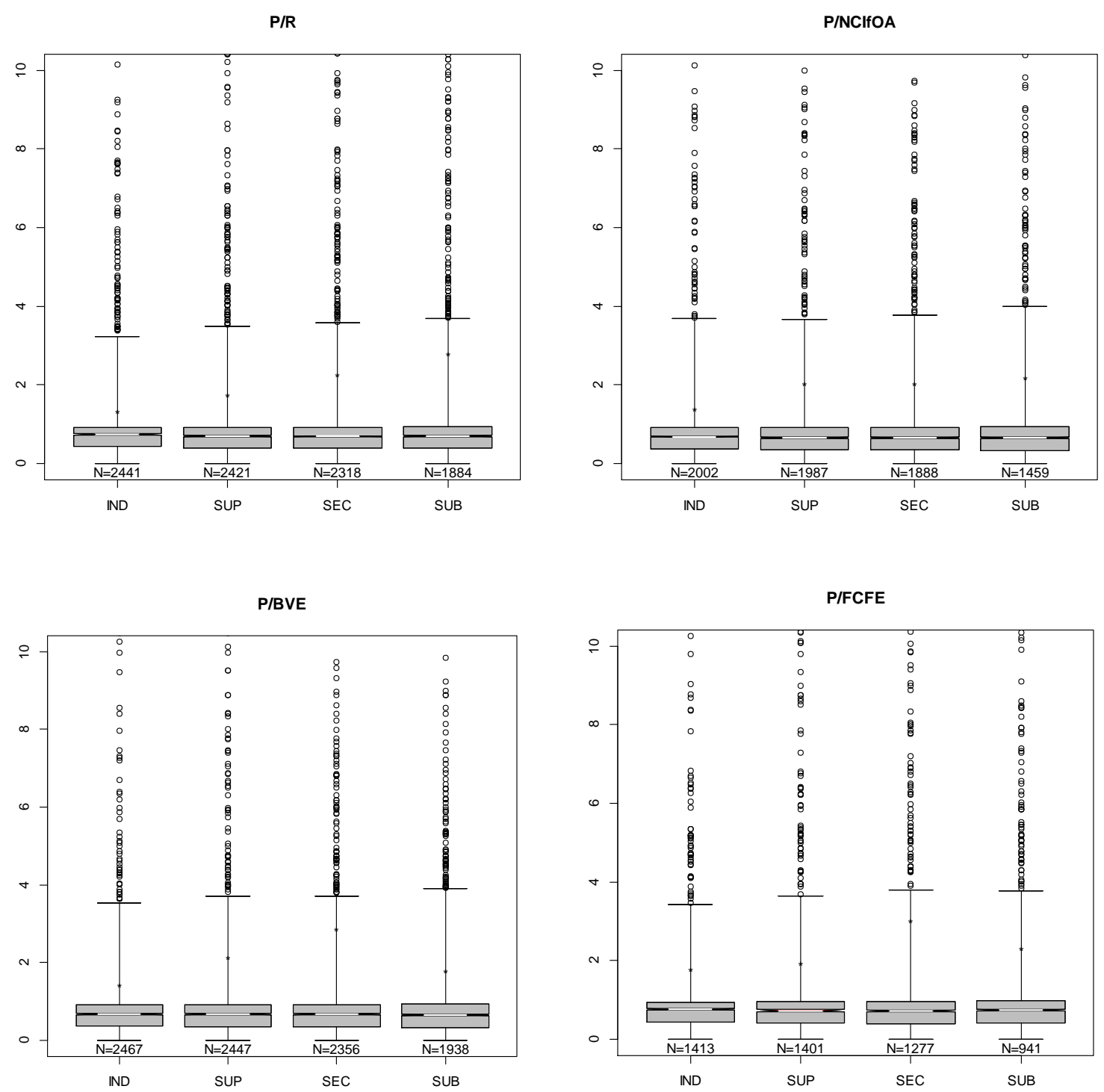

Figure 1 - continued 

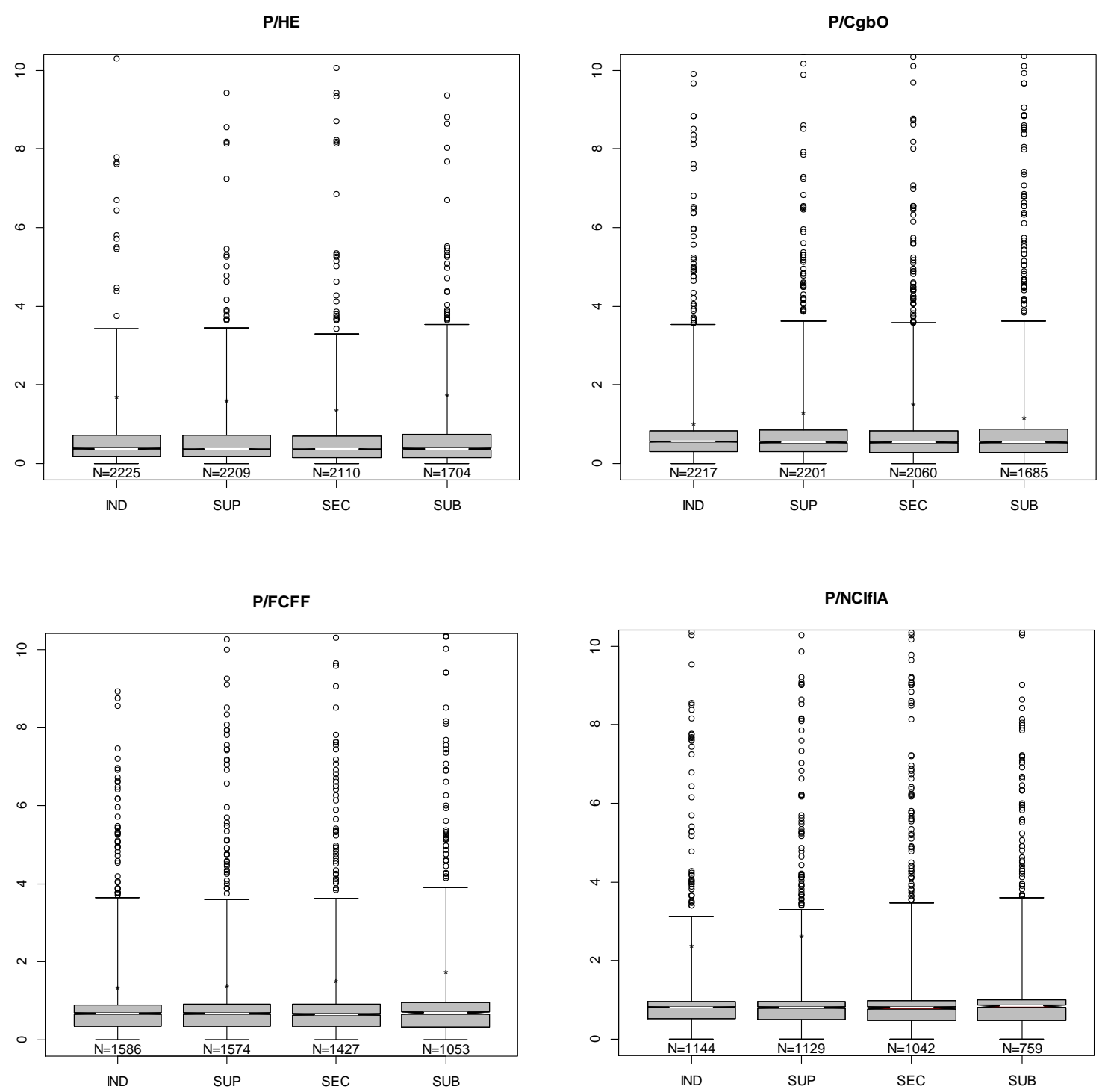

Figure 1 - continued 

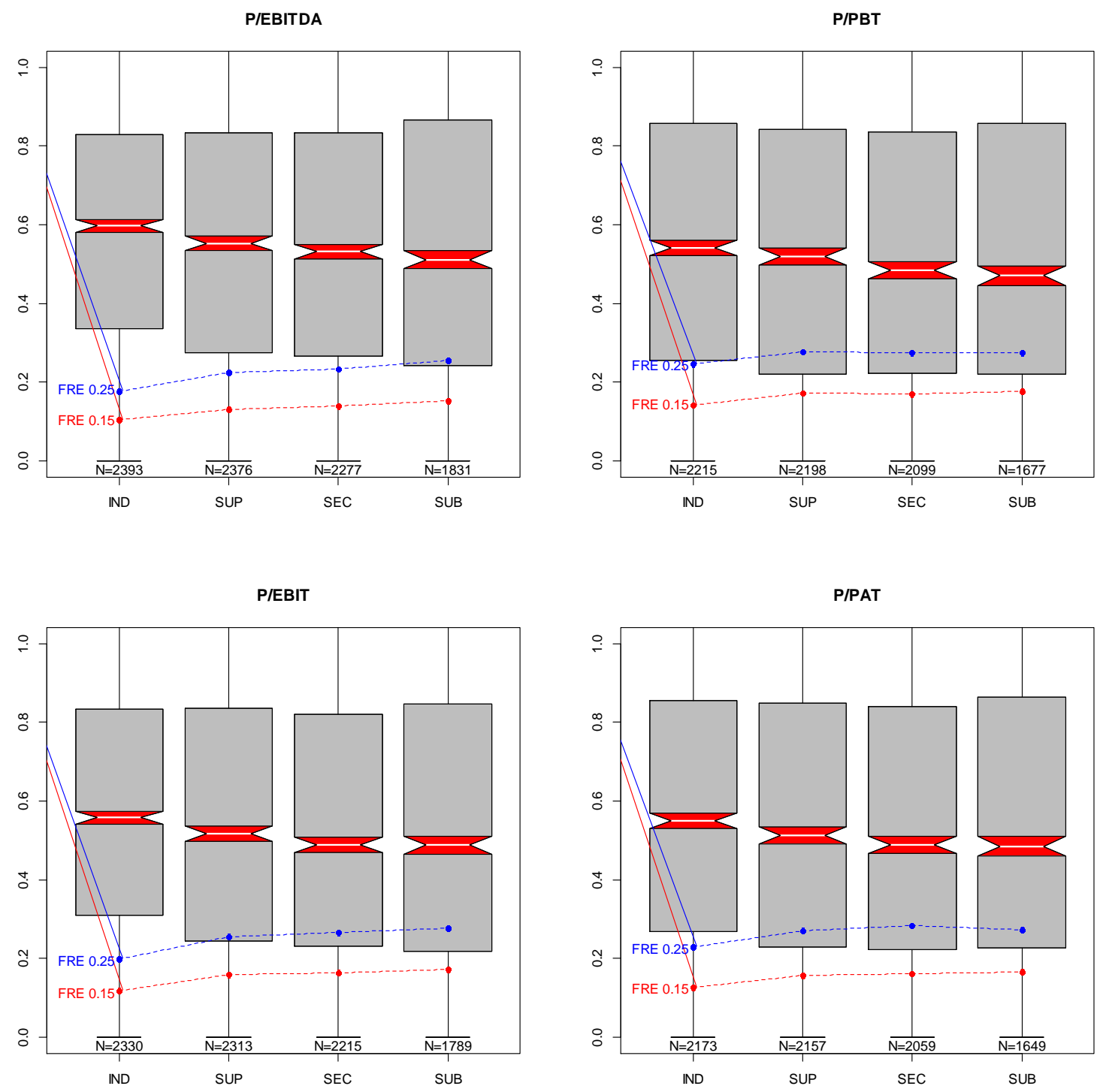

Figure 2: Valuation Accuracy Of Multiples - Absolute Median Valuation Errors And FREs 

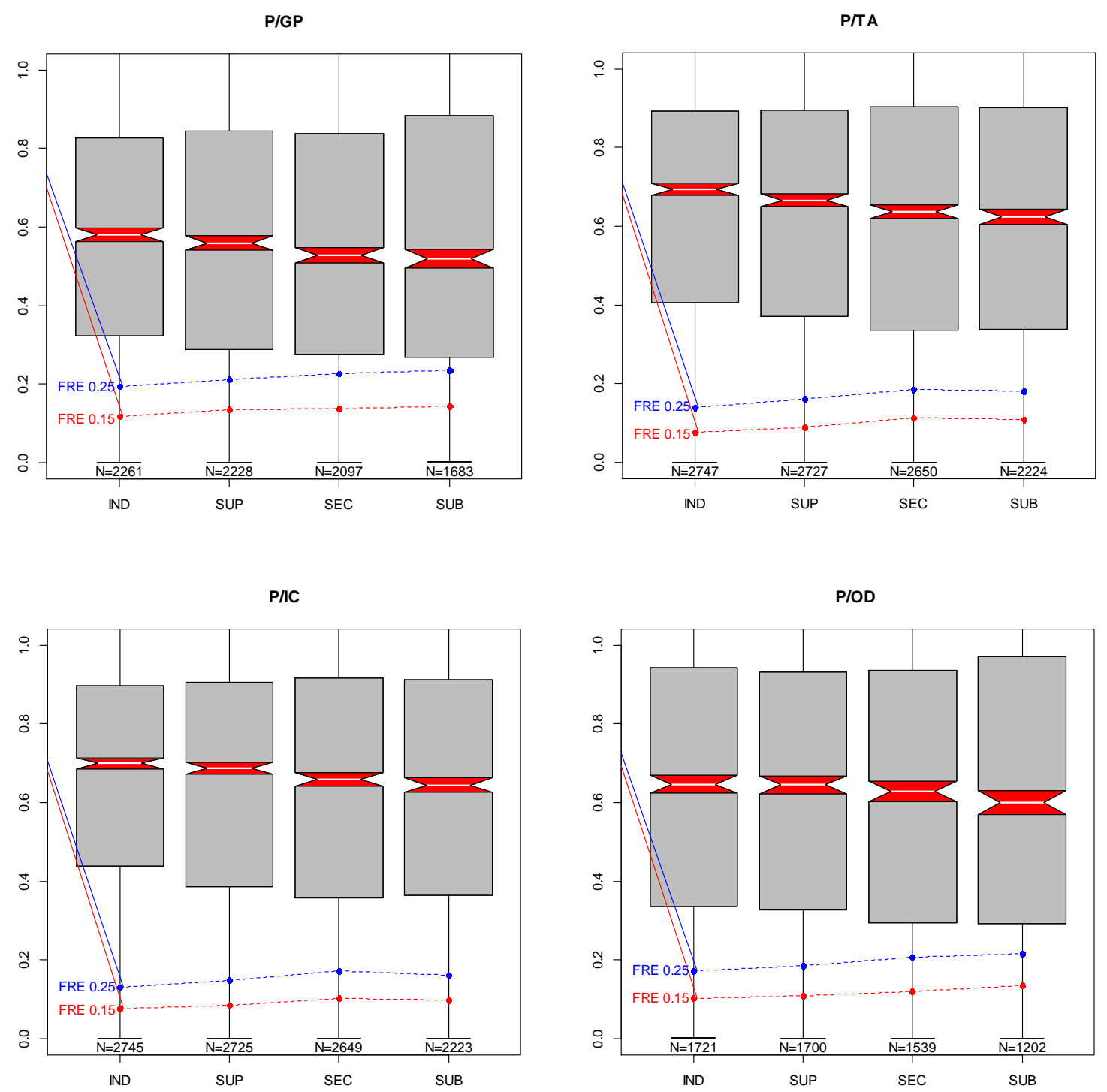

Figure 2 - continued 

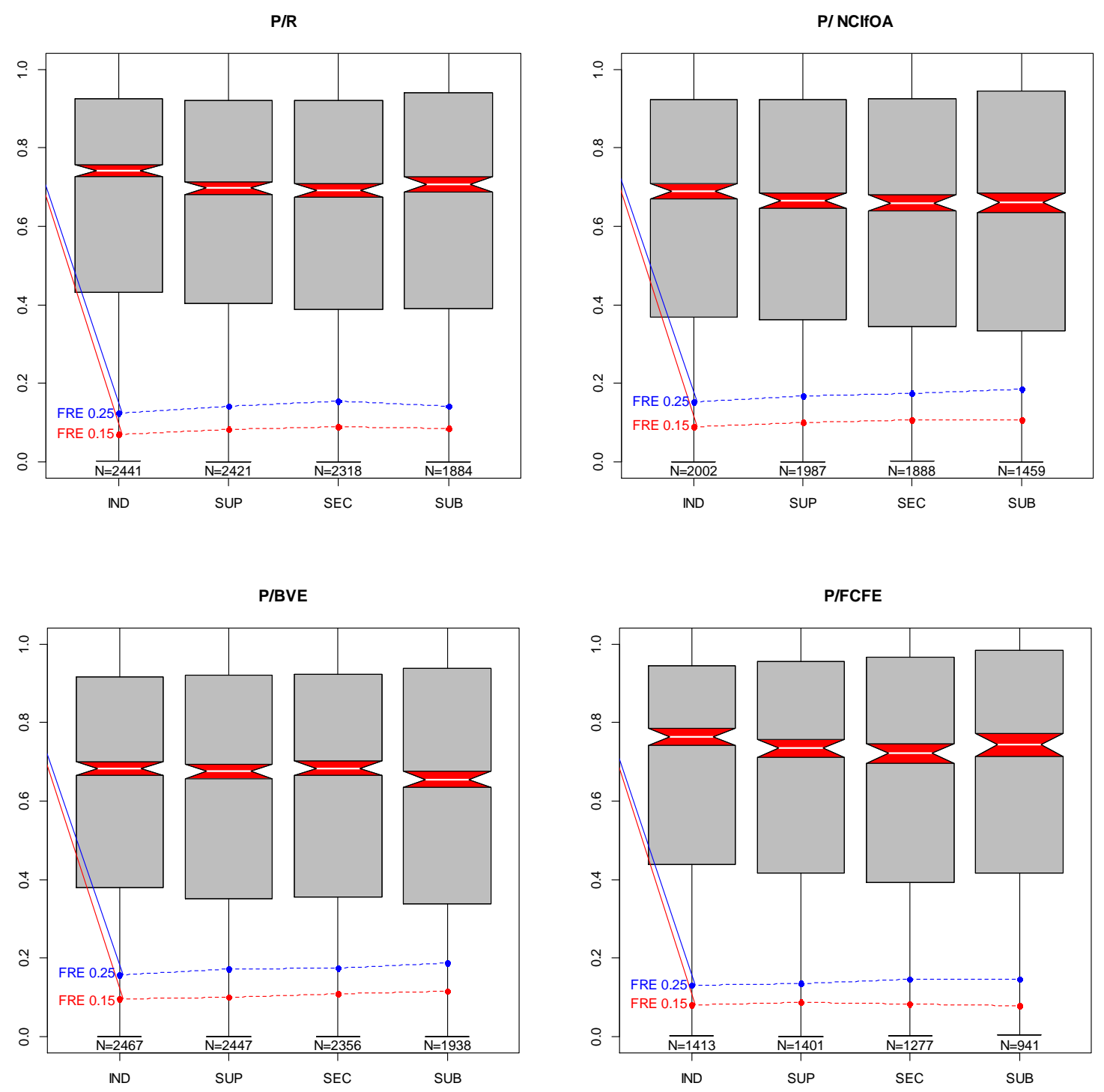

Figure 2 - continued 

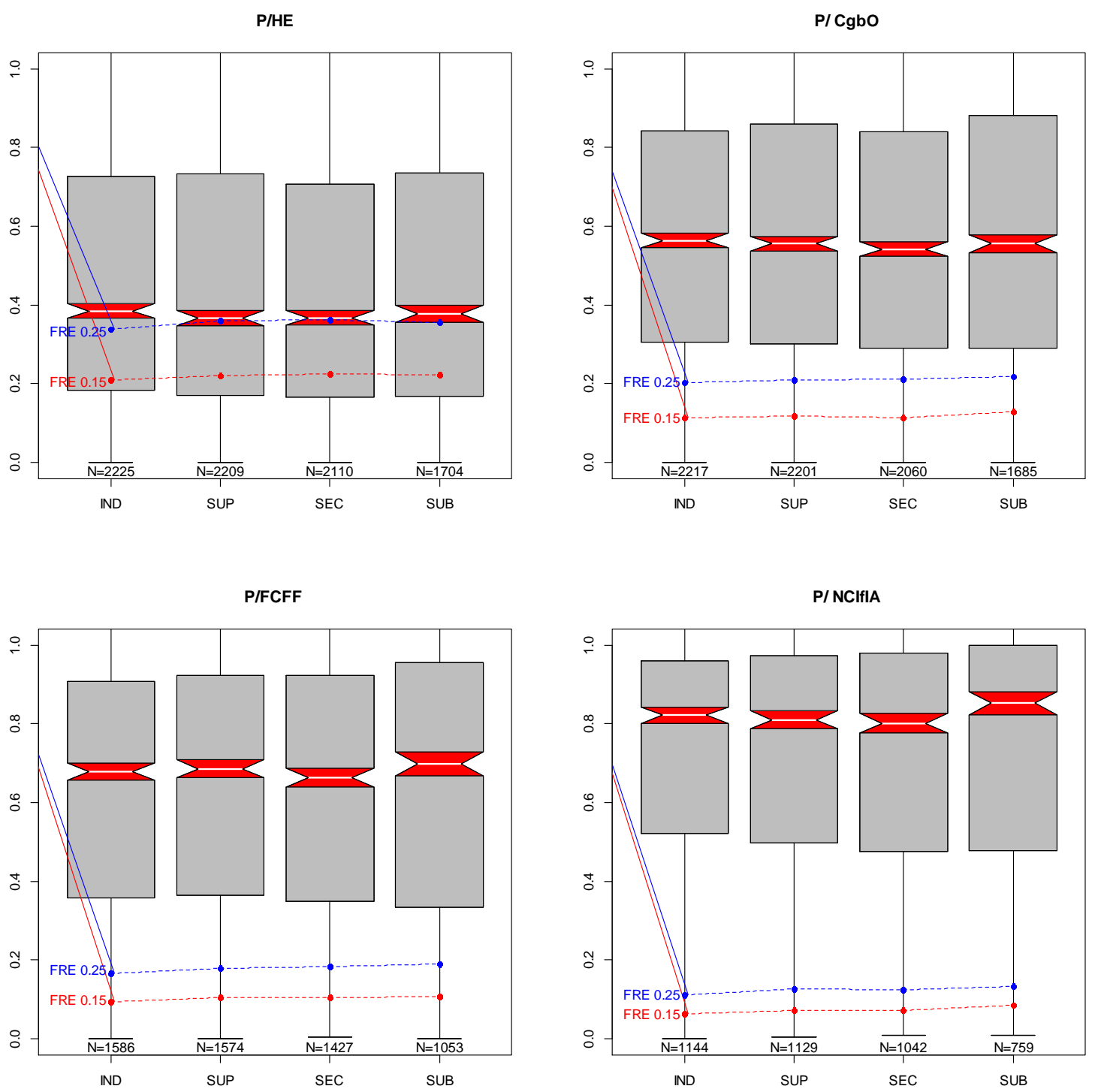

Figure 2 - continued 


\subsection{The impact of industry classification on valuation accuracy}

The medians and FREs of the four pools of valuation errors all rendered similar results. As is evident from Table 2 and the 16 boxplots in Figure 2, industry narrowing does increase valuation accuracy, since the median decreases and the FREs increase as the industry classification is narrowed. However, the boxplot notches in Figure 2 indicate that not all the multiples offered statistically significant improvements of the median at the 5\% confidence level, over all the industry classifications. When narrowing the industry classification from IND to SUP, only three multiples offer improvements of statistical significance; namely, EBITDA, EBIT and R. The number of multiples that offer statistically significant improvements at the 5\% confidence level increased to eight when narrowing the industry classification from IND to SEC. They were EBITDA, PBT, EBIT, PAT, GP, TA, IC and R. However, when the industry classification was narrowed further from IND to SUB, the number declined to seven, discarding R in the process. In order to quantify the potential increase in valuation accuracy that industry narrowing could offer, an industry value chain was created in Table 3.

Table 3: Industry Value Chain - Absolute Median Valuation Error And 25\% FRE Range

\begin{tabular}{|c|c|c|c|c|c|c|c|c|}
\hline \multicolumn{4}{|l|}{ Median } & \multirow{2}{*}{$\begin{array}{l}\text { Value } \\
\text { drivers }\end{array}$} & \multicolumn{4}{|l|}{ FRE 0.25} \\
\hline SUP & SEC & SUB & IMP & & SUP & SEC & SUB & IMP \\
\hline $3.65 \%$ & $5.58 \%$ & $1.44 \%$ & $10.68 \%$ & GP & $8.80 \%$ & $6.49 \%$ & $4.42 \%$ & $19.70 \%$ \\
\hline $7.44 \%$ & $3.80 \%$ & $3.78 \%$ & $15.02 \%$ & EBITDA & $26.80 \%$ & $3.37 \%$ & $10.01 \%$ & $40.19 \%$ \\
\hline $7.14 \%$ & $5.69 \%$ & $0.10 \%$ & $12.93 \%$ & EBIT & $29.05 \%$ & $3.75 \%$ & $4.63 \%$ & $37.43 \%$ \\
\hline $6.75 \%$ & $4.62 \%$ & 0.76\% & $12.13 \%$ & PAT & $18.19 \%$ & $1.70 \%$ & $-0.29 \%$ & $19.60 \%$ \\
\hline $3.99 \%$ & $6.74 \%$ & $2.87 \%$ & $13.60 \%$ & PBT & $12.71 \%$ & $-0.93 \%$ & $-0.11 \%$ & $11.67 \%$ \\
\hline $4.80 \%$ & $-0.22 \%$ & $-2.56 \%$ & $2.03 \%$ & $\mathrm{HE}$ & $6.47 \%$ & $0.75 \%$ & $-1.71 \%$ & $5.51 \%$ \\
\hline $3.98 \%$ & $4.46 \%$ & $1.93 \%$ & $10.37 \%$ & TA & $15.59 \%$ & $14.78 \%$ & $-3.00 \%$ & $27.36 \%$ \\
\hline $1.80 \%$ & $3.99 \%$ & $2.36 \%$ & $8.15 \%$ & IC & $13.38 \%$ & $16.32 \%$ & $-6.38 \%$ & $23.32 \%$ \\
\hline $1.13 \%$ & $-1.18 \%$ & $4.10 \%$ & $4.04 \%$ & BVE & $9.59 \%$ & $0.40 \%$ & $7.40 \%$ & $17.39 \%$ \\
\hline $5.96 \%$ & $0.77 \%$ & $-2.12 \%$ & $4.61 \%$ & $\mathbf{R}$ & $14.18 \%$ & $8.96 \%$ & $-7.84 \%$ & $15.31 \%$ \\
\hline $1.45 \%$ & $2.48 \%$ & $-2.53 \%$ & $1.41 \%$ & $\mathrm{CgbO}$ & $3.65 \%$ & $0.86 \%$ & $2.88 \%$ & $7.39 \%$ \\
\hline $3.55 \%$ & $0.90 \%$ & $-0.12 \%$ & $4.33 \%$ & NCIfOA & $10.05 \%$ & $4.30 \%$ & $6.64 \%$ & $20.98 \%$ \\
\hline $1.41 \%$ & $1.04 \%$ & $-6.29 \%$ & $-3.84 \%$ & NCIfIA & $13.94 \%$ & $-2.90 \%$ & $7.51 \%$ & $18.55 \%$ \\
\hline $0.14 \%$ & $2.59 \%$ & $4.55 \%$ & $7.27 \%$ & OD & $7.33 \%$ & $12.21 \%$ & $4.07 \%$ & $23.62 \%$ \\
\hline $3.82 \%$ & $1.81 \%$ & $-3.04 \%$ & $2.60 \%$ & FCFE & $4.13 \%$ & $7.41 \%$ & $-0.55 \%$ & $10.99 \%$ \\
\hline$-0.94 \%$ & $3.32 \%$ & $-5.25 \%$ & $-2.87 \%$ & FCFF & $8.44 \%$ & $2.50 \%$ & $3.58 \%$ & $14.53 \%$ \\
\hline $3.50 \%$ & $2.90 \%$ & $0.00 \%$ & $6.40 \%$ & Average & $12.64 \%$ & $5.00 \%$ & $1.95 \%$ & $19.60 \%$ \\
\hline $3.50 \%$ & $6.40 \%$ & $6.40 \%$ & & Cumulative & $12.64 \%$ & $17.64 \%$ & $19.60 \%$ & \\
\hline $94 \%$ & & & & 堷 & $100 \%$ & & & $100 \%$ \\
\hline & $88 \%$ & & $88 \%$ &. $\bar{\Xi}$ & & $88 \%$ & & \\
\hline & & $56 \%$ & & $\begin{array}{l}8 . \Xi \\
8\end{array}$ & & & $56 \%$ & \\
\hline SUP & SEC & SUB & IMP & & SUP & SEC & SUB & IMP \\
\hline
\end{tabular}

Positive percentages indicate, for each of the 16 multiples, to what extent the valuation accuracy of specific multiples increased when the industry classification was narrowed from one level to the next; i.e., from IND to SUP, from SUP to SEC and from SEC to SUB. Negative percentages indicate the opposite; i.e., to what extent the valuation accuracy of specific multiples decreased when the industry classification was narrowed. The highlighted 
percentages indicate the most optimal industry classifications for each multiple. The percentage improvement (IMP) between the widest (IND) and narrowest (SUB) industry classification is indicated in the last column. The histograms below the various industry classification columns indicate the percentage of multiples that experienced an increase in valuation accuracy when the industry classification was narrowed.

The average percentage increases in the median absolute valuation errors; i.e., the increase in valuation accuracy over all 16 multiples, when narrowing the industry classification from IND to SUP, SUP to SEC and SEC to SUB, were $3.50 \%, 2.90 \%$ and $-0.001 \%$, respectively. As is evident from these percentages, the magnitude of the increase in valuation accuracy declined as the industry classification was narrowed. The average increase in valuation accuracy over all 16 multiples when narrowing the industry classification from IND to SUP to SEC was $6.40 \%$. However, when narrowing the industry classification further from SEC to SUB the average change in valuation accuracy over all 16 value driver categories was negligible (-0.001\%). Therefore, the overall results suggest that the SEC classification is the most optimal industry classification. However, this may not be the case when each individual multiple is considered in isolation. The valuation accuracy of EBITDA, for example, increased with $3.78 \%$ when the industry classification was narrowed further from SEC to SUB.

An overall increase in valuation accuracy when the industry classification was narrowed from IND to SUB was observed in $88 \%$ of the multiples. The exceptions were NCIfIA ( $3.84 \%$ decrease) and FCFF (2.87\% decrease). An increase in valuation accuracy was observed for $94 \%$ of the multiples when the industry classification was narrowed from IND to SUP. The only exception was FCFF, which indicated a $0.94 \%$ decrease in valuation accuracy. The percentage of multiples that reflected an increase in valuation accuracy when the industry classification was narrowed from SUP to SEC was $88 \%$. The two multiples that did not reflect an increase in valuation accuracy were HE ( $0.22 \%$ decrease) and BVE (1.18\% decrease).

However, when narrowing the industry classification from SEC to SUB, the percentage of multiples that reflected an increase in valuation accuracy dropped significantly to 56\%. The seven multiples that failed to reflect an increase in valuation accuracy were $\mathrm{HE}$ ( $2.56 \%$ decrease), $\mathrm{R}(2.12 \%$ decrease), $\mathrm{CgbO}$ ( $2.53 \%$ decrease), NCIfOA ( $0.12 \%$ decrease), NCIfIA (6.29\% decrease), FCFE (3.04\% decrease) and FCFF (5.25\% decrease).

The top five individual multiples, that experienced the most significant increase in valuation accuracy when the industry classification was narrowed from IND through to SUB, were EBITDA (15.02\%), PBT (13.60\%), EBIT $(12.93 \%)$, PAT $(12.13 \%)$ and GP (10.68\%).

The analysis of the 0.15 and 0.25 FREs rendered similar results. The proportion of valuation errors in the $25 \%$ error range increased, on average, over all 16 multiples, when the industry classification was narrowed from IND to SUP, SUP to SEC and SEC to SUB. The percentage increases offered within the 25\% FRE range were $12.64 \%, 5.00 \%$ and $1.95 \%$, respectively. As with the median analysis, the magnitude of the increase in valuation accuracy declined as the industry classification was narrowed. The average increase in valuation accuracy over all 16 multiples, when narrowing the industry classification from IND to SUP to SEC to SUB, was $19.60 \%$. Although not elaborated on in this paper, the 15\% FRE range offered, on average, an even higher increase in valuation accuracy of $23.82 \%$. The overall results suggest that the SUB classification is the most optimal industry classification. However, as with the median, this will not be the case when each individual multiple is considered in isolation. The valuation accuracy of $\mathrm{R}$, for example, decreased with $7.84 \%$ when the industry classification was narrowed further from SEC to SUB.

The fractional error analysis indicated an overall increase in valuation accuracy in $100 \%$ of the multiples when the industry classification was narrowed from IND to SUB. A step-wise industry refining approach revealed that $100 \%$ of the multiples indicated an increase in valuation accuracy when the industry classification was narrowed from IND to SUP. The percentage of multiples that reflected an increase in valuation accuracy when the industry classification was narrowed from SUP to SEC was $88 \%$. The two multiples that failed to reflect an increase in valuation accuracy were PBT ( $0.93 \%$ decrease) and NCIfIA ( $2.90 \%$ decrease). However, as was the case with the median, when the industry classification was narrowed from SEC to SUB, the percentage of multiples that reflected an increase in valuation accuracy dropped significantly to 56\%. The seven multiples that did not reflect an increase in valuation accuracy were PAT $(0.29 \%$ decrease), PBT $(0.11 \%$ decrease), HE $(1.71 \%$ decrease), TA $(3.00 \%$ decrease), IC (6.38\% decrease), R (7.84\% decrease) and FCFE (0.55\% decrease). 
The top five individual multiples, that experienced the most significant increase in valuation accuracy when the industry classification was narrowed from IND through to SUB, were EBITDA (40.19\%), EBIT (37.43\%), TA (27.36\%), OD (23.62\%) and IC (23.32\%).

\section{CONCLUSION}

The primary aim of this paper was to establish whether narrower industry classifications increase the valuation accuracy of multiples. The secondary aim was to determine the potential improvement in valuation accuracy that industry narrowing may offer vis-à-vis wider industry classifications. The third aim was to determine the most optimal industry classification for peer group selection purposes. To this end, 16 multiples were constructed, covering four value driver categories; namely, earnings, book value, revenue and cash flow.

Data were extracted and screened from the McGregor BFA database and subsequently used to calculate a pool of valuation errors. Various measures of locality and dispersion were used to analyse the pooled valuation errors; i.e., the mean, the $25 \%$ percentile, the median, the $75 \%$ percentile and the 0.15 and 0.25 - FREs. The various industry classifications for each of the 16 multiples were compared in an attempt to establish which industry classifications produced the most accurate equity valuations.

The research results presented strong evidence in support of the use of narrower industry classifications when employing multiples to perform equity valuations. The absolute median valuation error and 25\% FRE indicated an overall increase in valuation accuracy when the industry classification was narrowed from IND to SUB over $88 \%$ and $100 \%$ of the multiples, respectively. The corresponding percentages when the industry classification was narrowed from IND to SUP, were $96 \%$ and $100 \%$ of the multiples, respectively. These improvements in valuation accuracy declined to $88 \%$ of the multiples when the industry classification was narrowed from SUP to SEC and to $56 \%$ of the multiples when the industry classification was narrowed from SEC to SUB. Therefore, the research results support the notion that narrower industry classifications explain market values better than wider industry classifications, which is in line with empirical evidence from developed markets.

The secondary aim was to determine the IMP in valuation accuracy that narrower industry classifications may offer vis-à-vis wider classifications. Based on the absolute median valuation errors and $25 \%$ FREs, the overall average IMP in valuation accuracy by employing narrower industry classifications lies between 6.40 and $19.60 \%$. Individual multiples demonstrated even more significant results. The P/EBITDA multiple, for example, indicated an improvement of $15.02 \%$ in the absolute median valuation error and $40.19 \%$ in the $25 \%$ FRE range. It is therefore evident that narrower industry classifications do improve valuation accuracy, but at varying degrees.

The third aim was to establish the most optimal industry classification for the selection of a peer group. The research results indicated that, on average, narrowing the industry classification beyond that of SEC added little, if any, value. This is in line with evidence from developed capital markets, which indicates that narrowing industry classifications beyond 3-digit codes, adds little value. However, the evidence does suggest that multiples have different optimal industry classifications and that, when individual multiples are considered in isolation, there may be value in narrowing the industry classification further to SUB, as was the case with the P/EBITDA multiple, for example.

The evidence therefore suggests that analysts in the South African market should consider employing the narrowest industry classification possible when constructing a peer group multiple. A narrower industry classification could provide an increase in valuation accuracy of up to $19.60 \%$, on average, which offers a significant improvement over wider industry classifications. The potential increase in valuation accuracy when consideration is given to individual multiples is even greater. The P/EBITDA multiple, for example, offers a potential increase in valuation accuracy of between $15.02 \%$ and $40.19 \%$ as the industry classification is narrowed from IND to SUB. Analysts who prefer specific multiples could perhaps even employ a SUB industry classification.

Although one may be inclined to pursue other, more diligent approaches to peer group selection, which may enhance the valuation accuracy of these multiples further, the focus of this paper was on the specific contribution that a narrower industry classification may offer in this regard. The investigation of further enhancing strategies is a topic for future research. 


\section{AUTHOR INFORMATION}

Mr Soon Nel lectures Finance at the University of Stellenbosch in South Africa. He is a qualified chartered accountant and holds a Master of Commerce degree in Economics and a Higher Diploma in Education. Soon's principal research interests are equity valuations, investment appraisals and mergers and acquisitions. He is currently registered for his PhD in Finance. E-mail: snel@ sun.ac.za (Corresponding author)

Prof Wilna Bruwer lectures Finance at the University of Stellenbosch in South Africa. She is a qualified chartered accountant and holds an MBA degree and a $\mathrm{PhD}$ in Finance. Her primary research interests include failure prediction, overtrading and cash flow. E-mail: $\underline{\text { bws1@sun.ac.za }}$

Prof Niel le Roux lectures Statistics at the University of Stellenbosch in South Africa. He holds various Master of Science degrees; namely, in Experimental Psychology, Mathematical Statistics and Geography. Niel also holds a $\mathrm{PhD}$ in Mathematical Statistics. His main research interests include multivariate statistical analysis, multidimensional scaling and graphical representation of multivariate data. E-mail: njlr@sun.ac.za

\section{REFERENCES}

1. Alford, A. (1992). The effect of the set of comparable companies on the accuracy of the price-earnings valuation method. Journal of Accounting Research, 30(1): 94-108.

2. Asquith, P., Mikhail, M.B. \& Au, A.S. (2005). Information content of equity analyst reports. Journal of Financial Economics, 75(2): 245-282.

3. Barker, R.G. (1999). Survey and market-based evidence of sector-dependence in analysts' preferences between the dividend yield and price-earnings ratio valuation models. Journal of Business Finance and Accounting, 26(3\&4): 393-418.

4. Beatty, R.P., Riffe, S.M. \& Thompson, R. (1999). The method of comparables and tax court valuations of private companies - An empirical investigation. Accounting Horizons, 13(3): 177-199.

5. Berkman, H., Bradhury, M.E. \& Ferguson, J. (2000). The accuracy of price earnings and discounted cash flow methods of IPO equity valuations. Journal of International Financial Management and Accounting, 11(2): 71-83.

6. Bhojraj, S. \& Lee, M.C. (2002). Who is my peer? A valuation-based approach to the selection of comparable companies. Journal of Accounting Research, 40(2): 407-439.

7. Bruner, F., Conroy, R.M., Estrada, J., Kritzman, M. \& Li, W. (2002). Introduction to Valuation in emerging markets. Emerging Markets Review, 3(4): 300-324.

8. Cheng, C.S.A. \& McNamara, R. (2000). The valuation accuracy of the price-earnings and price-book benchmark valuation methods. Review of Quantitative Finance and Accounting, 15(4): 349-370.

9. Damodaran, A. (2002). Investment valuation: Tools and techniques for determining the value of any asset. $2^{\text {nd }}$ edition. New York: John Wiley \& Sons, Inc.

10. Damodaran, A. (2006a). Damodaran on valuation: Security analysis for investment and corporate finance. $2^{\text {nd }}$ edition. New Jersey: John Wiley \& Sons, Inc.

11. Damodaran, A. (2006b). Valuation approaches and metrics: A survey of the theory and evidence. $2^{\text {nd }}$ edition. Hanover: Now Publishers, Inc.

12. Damodaran, A. (2009). The dark side of valuations. $2^{\text {nd }}$ edition. New Jersey: Pearson Education, Inc.

13. Dittmann, I. \& Maug, E. (2008). Biases and error measures: How to compare valuation methods. Working paper. Rotterdam: Erasmus University.

14. Eberhart, A.C. (2001). Comparable firms and the precision of equity valuations. Journal of Banking and Finance, 25(7): 1367-1400.

15. Fenn, G.W. \& Cole, R.A. (1994). Announcements of asset-quality problems and contagion effects in the life insurance industry. Journal of Financial Economics, 35(2): 181-198.

16. Fernández, P. (2001). Valuation using multiples. How do analysts reach their conclusions? Working paper. Madrid: IESE Business School.

17. Fuller, R.J. \& Kerr, H.S. (1981). Estimating the divisional cost of capital: An analysis of the pure-play technique. Journal of Finance, 36(5): 997-1009. 
18. Goedhart, M., Koller, T. \& Wessels, D. (2005). The right role for multiples in valuation. McKinsey on Finance, 15: 7-11.

19. Henschke, S. \& Homburg, C. (2009). Equity valuation using multiples: Controlling for differences between firms. Working paper. Cologne, University of Cologne.

20. Herrmann, V. \& Richter, F. (2003). Pricing with performance-controlled multiples. Schmalenbach Business Review, 55(3): 194-219.

21. Kaplan, S.N. \& Ruback, R.S. (1995). The valuation of cash flow forecasts: An empirical analysis. Journal of Finance, 50(4): 1059-1093.

22. Kim, M. \& Ritter, R. (1999). Valuing IPOs. Journal of Financial Economics, 53(3): 409-437.

23. Lang, L.H.P. \& Stulz, R.M. (1992). Contagion and competitive intra-industry effects of bankruptcy announcements: An empirical analysis. Journal of Financial Economics, 32(1): 45-60.

24. Lie, E. \& Lie, H. (2002). Multiples used to estimate corporate value. Financial Analysts Journal, 58(2): 4454.

25. Liu, J., Nissim, D. \& Thomas, J. (2002a). Equity valuation using multiples. Journal of Accounting Research, 40(1): 135-172.

26. Liu, J., Nissim, D. \& Thomas, J. (2002b). International equity valuation using multiples. Working paper. Los Angeles: University of California at Los Angeles (Anderson Graduate School of Management).

27. Minjina, D.I. (2008). Multiples and their use for equity valuation on European capital markets. Theoretical and Applied Economics, 11(11): 22-28.

28. Nel, W.S. (2009a). The use of multiples in the South African equity market: Is the popularity of the price earnings ratio justifiable from a sector perspective? Meditari Accountancy Research, 17(2): 101-115.

29. Nel, W.S. (2009b). Methods of choice in the valuation of ordinary shareholders' equity. Meditari Accountancy Research, 17(2): 117-135.

30. Nel, W.S. (2010). A South African perspective on the multiples of choice in the valuation of ordinary shareholders' equity: From theory to practice. African Journal of Business Management, 4(6): 930-941.

31. Pratt, S.P. (2005). How to use transactional databases for M\&A. Business Valuation Resources, Portland: Pacific Services Inc.

32. PricewaterhouseCoopers (PwC) (2010). Valuation Methodology Survey. [online] Available from http://www.pwc.co.za/en/assets/pdf/pwc-valuation-methodology-survey-2010.pdf (Accessed on 14 August 2012).

33. R Development Core Team (2012). R: A language and environment for Statistical computing. R Foundation for Statistical Computing, Vienna, Austria. ISBN 3-900051-07-0, URL http://www.Rproject.org/.

34. Roosenboom, P. (2007). How Do Underwriters Value Initial Public Offerings? An Empirical Analysis of the French IPO Market. Contemporary Accounting Research, 24(4): 1217- 1243.

35. Schreiner, A. (2007). Equity valuations using multiples: An empirical investigation. PhD dissertation, Austria, University of St Gallen 1-169.

36. Schreiner, A. \& Spremann, K. (2007). Multiples and their valuation accuracy in European equity markets. Working paper. Frankfurt: University of Saint Gallen.

37. Stowell, D. (2010). An introduction to investment banks, hedge funds and private equity. 1st edition. Burlington: Elsevier Inc. 


\section{APPENDIX A: ACRONYMS}

\section{$\underline{\text { Acronym/Abbreviation }}$}

BFA

BVE

$\mathrm{CgbO}$

$\varepsilon$

EBIT

EBITDA

FCFE

FCFF

FRE

GP

HE

$i$

IBES

IC

IMP

IND

JSE

MCap

$\mathrm{N}$

NCIfIA

NCIfOA

OD

$\mathrm{P}$

PAT

PBT

PwC

$\mathrm{R}$

SEC

SIC

SUB

SUP

$t$

TA

USA

$\lambda_{t}^{e}$

$\hat{\lambda}_{t}^{e}$

$\alpha_{i t}$

$V_{i t}^{e}$

$\hat{V}_{i t}^{e}$

\section{$\underline{\text { Description }}$}

Bureau of Financial Analysis

Book value of equity

Cash generated by operations

Error term

Earnings before interest and tax

Earnings before interest, tax, depreciation and amortisation

Free cash flow to equity

Free cash flow to the firm

Fractional error

Gross profit

Headline earnings

Company $i$

Institutional Brokers Estimation System

Invested capital

Potential percentage improvement

Industry

Johannesburg Stock Exchange

Market capitalisation

Number of observations

Net cash inflow from investing activities

Net cash inflow from operating activities

Ordinary dividends

Market price

Profit after tax

Profit before tax

PricewaterhouseCoopers

Revenue

Sector

Standard Industry Classification

Subsector

Supersector

Time period $t$

Total assets

United States of America

Actual multiple

Estimated peer group multiple at time period $t$

Actual value driver

Actual value of equity of company $i$ at time period $t$

Estimated value of equity of company $i$ at time period $t$ 


\section{APPENDIX B: CLASSIFICATION OF VARIABLES}

The classification of the variables was mostly derived from the descriptions as presented in the McGregor BFA user manuals.

\section{Market Price Variable}

1. MCap represents the market value of a company's issued ordinary share capital. MCap is calculated by multiplying the market price per share as at the company's financial year end with the issued volume of shares at the same date.

\section{Earnings-based Multiples}

2. GP represents and is calculated as the difference between sales or revenue and the cost of sales.

3. EBITDA represents a company's earnings before interest paid, taxation, depreciation and amortisation. It is calculated by taking GP, adding other income (excluding income from associates) and deducting all expenses, but adding back interest paid, taxation, depreciation and amortisation.

4. EBIT represents a company's earnings before interest paid and taxation. It is calculated by taking EBITDA and deducting depreciation and amortisation.

5. PBT represents a company's net profit, including realised profits and all losses of an extraordinary nature, after interest paid but before taxation. It is calculated by taking EBIT and deducting interest paid.

6. PAT represents a company's net profit, including realised profits and all losses of an extraordinary nature, after interest paid and taxation. It is calculated by taking PBT and deducting taxation.

7. HE represents a company's earnings generated by normal operational activities. It is calculated by taking PAT and adding back profits/losses associated with non-core operational activities, such as the sale of fixed assets or the termination of discontinued operations.

\section{Book Value-based Multiples}

8. TA represents the total of all the assets employed by the company. It is calculated by adding total fixed assets, total long-term investments and total current assets.

9. IC represents the total cash investment by fund providers. It is calculated by deducting cash and cash equivalents from TA.

10. BVE represents the equity of the ordinary shareholders. It is calculated by adding ordinary share capital and reserves; and deducting the cost of control of subsidiaries and intangible assets.

\section{Revenue-based Multiple}

11. Revenue represents the gross sales of the company.

\section{Cash Flow-based Multiples}

12. CgbO represents pre-tax cash flows net of working capital expenditure as per the cash flow statement.

13. NCIfOA represents post-tax operational cash flows. It is calculated by taking $\mathrm{CgbO}$ and deducting net interest, net dividends and income taxation.

14. NCIfIA represents post-tax operational cash flows net of fixed capital expenditure. It is calculated by taking NCIfOA and deducting acquisitions of fixed capital items net of capital gains tax.

15. OD represents the amount of dividends paid to ordinary shareholders as per the cash flow statement.

16. FCFF represents post-tax cash flows that are available to be distributed to all the fund providers of a company, net of capital expenditure to grow or maintain the business. It is calculated by taking NCIfIA and adding back non-operational items, such as net interest and net dividends.

17. FCFE represents post-tax cash flows that are available to be distributed to all the equity fund providers of a company, net of capital expenditure to grow or maintain the business. It is calculated by taking FCFF and adding/deducting debt capital movements and interest paid. 
NOTES 